ISSN 0258-7122

Bangladesh J. Agril. Res. 37(4): 573-582, December 2012

\title{
MULTIVARIATE ANALYSIS IN ONION (Allium cepa L.)
}

\author{
M. H. RASHID ${ }^{1}$, A. K. M. A. ISLAM ${ }^{2}$, M. A. K. MIAN ${ }^{3}$ \\ T. HOSSAIN $^{4}$ AND M. E. KABIR ${ }^{5}$.
}

\begin{abstract}
Thirty genotypes collected from India, Burma, and Bangladesh were studied for thier genetic divergence using Mahalanobi's $\mathrm{D}^{2}$ and Rao's canonical analysis. Altogether five clusters were formed. The pattern of distribution of genotypes into five clusters was random demonstrating that the geographical isolation might not be the only factor causing genetic diversity. Leaf length and sulfur content contributed predominantly towards genetic divergence. Cluster III recorded the highest means for number of leaves per plant, leaf length, bulb length, plant height, and bulb yield. The results obtained from $\mathrm{D}^{2}$ analysis were confirmed by canonical analysis. The genotype $\mathrm{G}_{12}$ showed highest mean performance for moisture content $(88.49 \%), \mathrm{G}_{13}$ for leaf length $(39.06 \mathrm{~cm}), \mathrm{G}_{15}$ for neck diameter at vegetative stage $(11.21 \mathrm{~mm})$, bulb length $(49.09 \mathrm{~mm})$, plant height $(64.82 \mathrm{~cm})$ and as well as bulb yield $(13.17 \mathrm{t} / \mathrm{ha}), \mathrm{G}_{19}$ for percent sulfur content $(0.84)$ and $\mathrm{G}_{26}$ for number of leaves per plant (12), respectively.
\end{abstract}

Keywords: onion, multivariate analysis, genetic divergence.

\section{Introduction}

Onion (Allium cepa L.) belongs to the family Amaryllidaceae and is one of the most important spices as well as vegetable crop in the world. Onion ranks first among the spice crops grown in Bangladesh. Yield of any crop is a complex character which depends on a number of agronomic traits and is influenced by many factors which could be genetic or environmental (Uddin et al., 1985).

Information on genetic divergence among plant materials is vital to a plant breeder for selection of parents for hybridization. It is an established fact that genetically diverse parents are likely to contribute desirable segregants and/or to produce high heterotic cross. More diverse the parents, greater are the chances of obtaining higher heterotic $\mathrm{F}_{1} \mathrm{~S}$ and broader spectrum of variability in the segregating generations (Arunachalam et al., 1984). Improvement in yield and quality is normally achieved by selecting genotypes with desirable characters existing in the nature or by hybridization. The parent identified on the basis of

\footnotetext{
${ }^{1}$ Senior Scientific Officer, ORC, Bangladesh Agricultural Research Institute (BARI), Gazipur, ${ }^{2}$ Assistant Professor, Department of Genetics and Plant Breeding, Bangabandhu Sheikh Mujibur Rahman Agricultural University (BSMRAU), Gazipur, ${ }^{3}$ Professor, Department of Genetics and Plant Breeding, BSMRAU, Gazipur, ${ }^{4}$ Professor, Department of Crop Botany, BSMRAU, Gazipur, ${ }^{5} \mathrm{MS}$ Student, Department of Genetics and Plant Breeding, BSMRAU, Gazipur, Bangladesh
} 
divergence analysis would be more promising. Mohanthy (1999, 2001, 2002), Mohanty and Prusti (2002) have reported some related results in onion. Those studies did not include any Bangladeshi cultivars/genotypes. In Bangladesh context, the information on this aspect of onion is not sufficient. A study including some genotype collected from different sources would be very important in breeding varieties for Bangladesh. The present investigation was undertaken to estimate the nature and magnitude of genetic diversity of onion genotypes and subsequent use in onion improvement programs.

\section{Materials and Method}

Genetically pure and physically healthy seeds of these genotypes were obtained from Bangabandhu Sheikh Mujubur Rahman Agricultural University germplasm collections. One standard variety Taherpuri was used as the check variety. Source and bulb characteristics of the genotypes with thier origin are mentioned in Table 1.

Table 1. Bulb characteristics of $\mathbf{3 0}$ genotypes of onion with their origin.

\begin{tabular}{|c|c|c|c|}
\hline SL No. & $\begin{array}{c}\text { Accession } \\
\text { number }\end{array}$ & Origin & Bulb characteristics \\
\hline 1 & 038 & India & Medium, light brown red, closed neck, flat \\
\hline 2 & 012 & Myanmar & Medium, light brown red, closed neck \\
\hline 3 & 019 & Myanmar & Medium, brown red, closed neck \\
\hline 4 & 022 & India & Large, light brown red, closed neck, flat \\
\hline 5 & 016 & Burma & Medium, light red, closed neck round \\
\hline 6 & 001 & Pabna & Medium, brown red, closed neck, flat \\
\hline 7 & 017 & India & Medium, light brown red, closed neck \\
\hline 8 & 007 & India & Large, light pink, almost flat neck \\
\hline 9 & 032 & Rajshahi & Medium, light brown red, closed neck \\
\hline 10 & 035 & Swandip & Very small, brown red, closed neck \\
\hline 11 & 033 & Rajshahi & Medium, light brown, closed neck, flat \\
\hline 12 & 006 & India & Large, elongate, close neck, pink \\
\hline 13 & 024 & India & Large, deep pink, close neck, elongate \\
\hline 14 & 039 & Bangladesh & Medium, brown red, flat \\
\hline 15 & 023 & India & Medium, light brown branched \\
\hline 16 & 039self & Bangladesh & Medium, brown red, closed neck, round \\
\hline 17 & 011 & Unknown & Large, deep pink, close neck, \\
\hline 18 & 021 & Mymensingh & Medium, brown red, closed neck, flat \\
\hline 19 & Selected/099 & Burma & Medium-large, light brown red, flat \\
\hline 20 & 010 & Burma & Medium, brown red, closed neck, round \\
\hline 21 & 014 & Burma & Medium, brown red, open neck, flat \\
\hline 22 & Taherpuri & Bangladesh & Medium, deep brown red, flat \\
\hline 23 & 003 & Faridpur & Medium, light brown branched \\
\hline 24 & 004 & India & Medium deep pink, close neck \\
\hline 25 & 018 & India & Small, brown neck, close neck \\
\hline 26 & 015 & India & Medium, brown red, closed neck, flat \\
\hline 27 & 002self & Pabna & Medium, light brown red, closed neck, flat \\
\hline 28 & 025 & India & Large, brown red, flat type, closed neck \\
\hline 29 & 002 & Pabna & Medium, brown red, closed neck, flat \\
\hline 30 & 040self & Bangladesh & Medium, light brown red, flat \\
\hline
\end{tabular}


Seedlings of each genotype were raised in $3 \mathrm{~m} \times 1 \mathrm{~m}$ unit bed with normal care. Afterwards, 49 days old seedling were transplanted in the main field in a RCB design with three replications at the experimental field of Bangabandhu Sheikh Mujibur Rahman Agricultural University, Gazipur during rabi season of 2006-2007. Each genotype was grown in 10 rows of two-meter length with $20 \mathrm{~cm}$ $\times 8 \mathrm{~cm}$ spacing. The data were recorded from 10 competitive randomly selected plants from each plot on number of leaves per plant, leaf length, neck diameter at vegetative stage, bulb length, moisture content, sulfur content, plant height, and bulb yield. Plot means were used for statistical analysis. Genetic diversity was studied following Mahalanobis generalized distance $\left(\mathrm{D}^{2}\right)$ extended by Rao (1952). Canonical analysis was done according to Rao (1964) to confirm the results of cluster and $\mathrm{D}^{2}$ analysis. Statistical analyses were carried out using MSTAT C Programme.

\section{Results and Discussion}

The analysis of variance showed significant differences among the 30 genotypes of onion at $1 \%$ level indicating the presence of notable genetic variability among the genotype and therefore, multivariate analysis was carried out. Thirty genotypes were morphologically characterized mainly on the basis of bulb character viz., bulb colour, shape, neck diameter, etc. All the genotype were different for considering characters and were recorded properly (Table 1). Mean performance of the genotypes are shown in Table 3. The genotype G15 (India) produced the highest bulb yield followed by G30 (Bangladesh) and G5 (Burma). Higher bulb yield of G15 genotype is related with the highest neck diameter at vegetative stage $(\mathrm{mm})$ and the highest bulb length $(\mathrm{mm})$. Genotype G15 also belongs with the largest leaf length $(38.68 \mathrm{~cm})$ and relatively higher number of leaves (11.43) which increases its photosynthetic areas as well as the highest bulb yield.

Table 2. Estimation of genetic components of 8 yield related characters in onion.

\begin{tabular}{c|c|c|c|c|c|c|c|c}
\hline Component & NL & $\begin{array}{c}\text { LL } \\
(\mathrm{cm})\end{array}$ & $\begin{array}{c}\text { NDV } \\
(\mathrm{mm})\end{array}$ & $\begin{array}{c}\mathrm{BL} \\
(\mathrm{mm})\end{array}$ & $\begin{array}{c}\text { Water } \\
(\%)\end{array}$ & $\begin{array}{c}\mathrm{S} \\
(\%)\end{array}$ & $\begin{array}{c}\text { PH } \\
(\mathrm{cm})\end{array}$ & $\begin{array}{c}\text { Bulb } \\
\text { yield } \\
(\mathrm{t} / \mathrm{ha})\end{array}$ \\
\hline Range & $7.90-$ & $23.95-$ & $7.00-$ & $30.01-$ & $83.00-$ & $0.42-$ & $47.32-$ & $5.39-$ \\
& 12.10 & 40.09 & 11.96 & 49.98 & 89.74 & 0.85 & 66.50 & 13.30 \\
Mean & 10.18 & 30.23 & 9.71 & 39.82 & 86.69 & 0.57 & 55.27 & 8.55 \\
$\sigma^{2} \mathrm{~g}$ & 0.62 & 12.33 & 0.85 & 10.84 & 1.93 & 0.01 & 20.90 & 3.95 \\
$\sigma^{2} \mathrm{p}$ & 0.82 & 13.00 & 0.93 & 11.39 & 3.30 & 0.01 & 21.48 & 4.01 \\
$\mathrm{GCV}$ & 7.73 & 11.61 & 9.48 & 8.22 & 1.60 & 15.36 & 23.26 & 8.27 \\
$\mathrm{PCV}$ & 8.84 & 11.93 & 9.93 & 8.43 & 2.09 & 15.46 & 23.43 & 8.39 \\
$\mathrm{~h}^{2} \mathrm{~b}$ & 75.65 & 94.86 & 91.27 & 95.13 & 58.54 & 98.79 & 97.29 & 98.54 \\
$\mathrm{GA}(5 \%)$ & 1.41 & 7.05 & 1.81 & 6.61 & 2.16 & 0.18 & 9.29 & 4.06 \\
$\mathrm{GA} \%$ mean & 17.74 & 29.86 & 23.92 & 21.16 & 3.20 & 40.31 & 21.54 & 60.95 \\
\hline F-value & $* *$ & $* *$ & $* *$ & $* *$ & $* *$ & $* *$ & $* *$ & $* *$ \\
$\mathrm{CV}(\%)$ & 4.38 & 2.70 & 2.93 & 1.83 & 1.34 & 4.14 & 1.38 & 2.83 \\
\hline
\end{tabular}


Table 3. Mean performance of different yield contributing character of onion.

\begin{tabular}{c|r|c|r|c|c|c|c|r}
\hline Genotype & $\begin{array}{c}\text { NL } \\
(\text { no. })\end{array}$ & $\begin{array}{c}\text { LL } \\
(\mathrm{cm})\end{array}$ & $\begin{array}{r}\text { NDV } \\
(\mathrm{mm})\end{array}$ & $\begin{array}{c}\text { BL } \\
(\mathrm{mm})\end{array}$ & $\begin{array}{c}\text { Water } \\
(\%)\end{array}$ & $\begin{array}{c}\mathrm{S} \\
(\%)\end{array}$ & $\begin{array}{c}\text { PH } \\
(\mathrm{cm})\end{array}$ & $\begin{array}{r}\text { Bulb } \\
\text { yield } \\
(\mathrm{t} / \mathrm{ha})\end{array}$ \\
\hline G1 & 10.47 & 31.26 & 9.43 & 41.54 & 86.08 & 0.52 & 53.21 & 10.25 \\
G2 & 9.37 & 27.80 & 10.38 & 41.23 & 86.54 & 0.54 & 54.11 & 9.25 \\
G3 & 10.30 & 33.80 & 10.60 & 47.50 & 87.65 & 0.58 & 63.45 & 10.38 \\
G4 & 10.07 & 31.97 & 10.82 & 42.09 & 87.02 & 0.55 & 60.21 & 9.00 \\
G5 & 10.99 & 31.08 & 9.95 & 45.72 & 87.52 & 0.58 & 58.77 & 11.95 \\
G6 & 11.07 & 31.81 & 9.88 & 39.44 & 87.56 & 0.53 & 55.17 & 6.42 \\
G7 & 10.00 & 25.40 & 10.95 & 41.28 & 86.98 & 0.56 & 56.70 & 7.13 \\
G8 & 10.20 & 30.65 & 8.90 & 39.70 & 86.21 & 0.57 & 54.01 & 8.40 \\
G9 & 9.47 & 29.30 & 8.47 & 35.69 & 84.60 & 0.48 & 49.71 & 7.38 \\
G10 & 9.98 & 27.98 & 9.76 & 37.03 & 86.22 & 0.57 & 49.53 & 8.18 \\
G11 & 9.10 & 29.15 & 10.20 & 35.22 & 88.49 & 0.47 & 48.31 & 8.07 \\
G12 & 8.57 & 27.52 & 7.73 & 30.82 & 87.20 & 0.48 & 51.00 & 5.74 \\
G13 & 11.13 & 39.06 & 10.35 & 41.99 & 84.72 & 0.51 & 59.53 & 8.22 \\
G14 & 10.03 & 29.04 & 10.10 & 36.48 & 88.29 & 0.77 & 55.53 & 8.23 \\
G15 & 11.43 & 38.68 & 11.21 & 49.09 & 86.16 & 0.72 & 64.82 & 13.17 \\
G16 & 9.60 & 25.23 & 9.93 & 40.57 & 85.70 & 0.52 & 55.24 & 9.66 \\
G17 & 10.80 & 25.67 & 8.57 & 40.66 & 87.06 & 0.44 & 55.77 & 7.25 \\
G18 & 8.58 & 30.06 & 7.83 & 36.92 & 87.65 & 0.61 & 48.10 & 6.82 \\
G19 & 9.85 & 28.46 & 8.35 & 39.03 & 88.42 & 0.84 & 58.94 & 8.11 \\
G20 & 10.90 & 25.98 & 10.15 & 40.66 & 85.98 & 0.51 & 54.76 & 7.22 \\
G21 & 9.90 & 28.05 & 9.18 & 37.97 & 85.25 & 0.58 & 57.09 & 5.82 \\
G22 & 10.90 & 27.89 & 9.34 & 37.30 & 86.12 & 0.63 & 49.98 & 9.76 \\
G23 & 9.77 & 31.08 & 10.08 & 36.67 & 87.65 & 0.62 & 53.12 & 9.69 \\
G24 & 10.87 & 30.31 & 9.75 & 43.87 & 88.27 & 0.54 & 55.84 & 8.17 \\
G25 & 10.57 & 29.48 & 9.22 & 39.78 & 85.19 & 0.57 & 50.21 & 6.73 \\
G26 & 11.60 & 31.34 & 10.14 & 43.11 & 86.59 & 0.56 & 57.53 & 11.01 \\
G27 & 9.67 & 28.13 & 8.94 & 37.04 & 86.68 & 0.60 & 50.19 & 6.41 \\
G28 & 10.21 & 29.83 & 9.16 & 31.58 & 86.30 & 0.50 & 62.53 & 9.33 \\
G29 & 8.77 & 33.52 & 11.03 & 43.02 & 86.44 & 0.61 & 53.02 & 5.79 \\
G30 & 11.30 & 37.60 & 10.95 & 41.62 & 86.44 & 0.53 & 61.84 & 12.86 \\
\hline & & & & & & & & \\
\hline
\end{tabular}

$\mathrm{NL}=$ Number of leaves per plant, LL $=$ Leaf length $(\mathrm{cm}), \mathrm{NDV}=$ Neck diameter at vegetative stage $(\mathrm{mm}), \mathrm{BL}=$ Bulb length $(\mathrm{mm}), \mathrm{S}=$ Sulfur percentages, $\mathrm{PH}=$ Plant height $(\mathrm{cm})$.

\section{Principal component analysis}

Principal component analysis was carried out with 30 genotypes of onion. First 3 eigen values for 3 principal coordination axes of genotypes accounted for 58.96 cumulative percentage. The first 33.08 and the second 15.33 eigen values gave 48.41 . 
Table 4. Eigen values and percentage of variation for corresponding eight component characters in 30 genotypes of onion.

\begin{tabular}{l|c|c|c}
\hline Principal component axis & Eigen values & $\begin{array}{c}\text { Percentage of total } \\
\text { variation account for }\end{array}$ & $\begin{array}{c}\text { Cumulative } \\
\text { percentages }\end{array}$ \\
\hline Number of leaves per plant & 5.2927 & 33.08 & 33.08 \\
Leaf length (cm) & 2.4531 & 15.33 & 48.41 \\
Neck diameter at vegetative & 1.6878 & 10.55 & 58.96 \\
stage (mm) & 1.4798 & 9.25 & 68.21 \\
Bulb length (mm) & 1.4590 & 9.12 & 77.33 \\
Water content (\%) & 1.3326 & 8.33 & 85.66 \\
Sulfur content (\%) & 1.2574 & 7.86 & 93.52 \\
Plant height (cm) & 1.0350 & 6.47 & 99.99 \\
Bulb yield (t/ha) & & & \\
\hline
\end{tabular}

A two dimensional scattered plotting diagram (Fig. 1) was developed on the basis of the $Z_{1}$ and $Z_{2}$ values of two principal coordinates axes I and II (Fig. 1). In the scattered diagram, it is apparently shows that 30 genotypes are scattered in different clusters it confirms their clustering pattern, and differentiation of genotypes belonging to the different clusters.

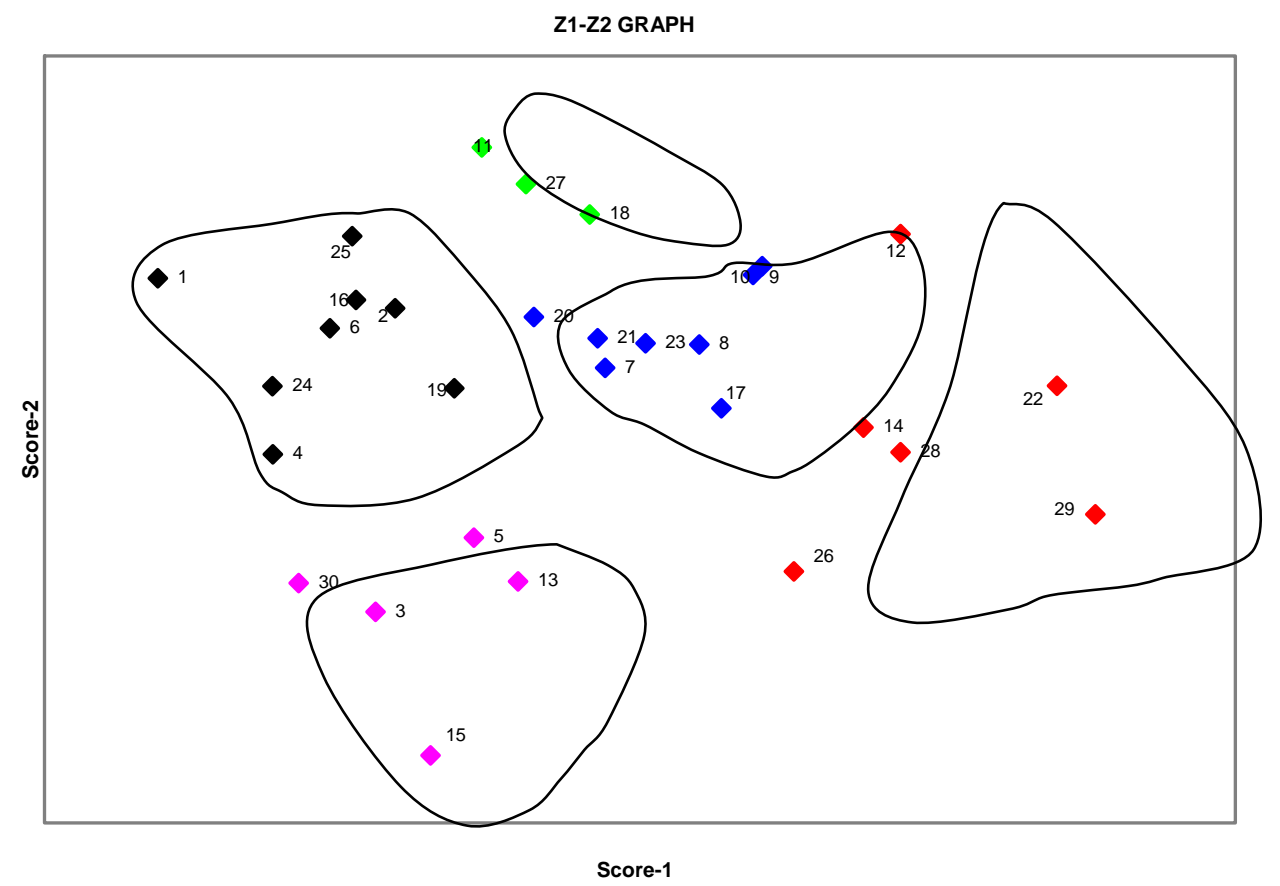

Fig. 1. Scatter distribution of 30 genotypes of onion based on their principal component scores super imposed with clustering. 


\section{Principal coordinate analysis}

The results obtained from principal coordinate analysis showed that longest inter genotypic distance remained between G12 and G30 (1.2299) followed by G18 and G23 (1.1826) and the shortest between G3 and G5 (0.2055) followed by G5 and G26 (0.2551) (Table 5). These inter genotypic distances were used in computation of intra-cluster distances on the basis of the suggestion forwarded by Singh and Choudhary (1977). The highest genotypic distance belonging genotypes may be subjected to use in hybridization programmes. The genotype G18 and G15 may produce dream child of a breeder. The lowest genotypic distance belonging genotypes G3 and G16 may be used to obtain homozygous population.

Table 5. Ten (10) highest and 10 lowest distance among genotypes.

\begin{tabular}{l|c}
\hline Genotype to Genotype & Distances \\
\hline a.10 highest inter genotypic distances & \\
G12-006---G30-040Self & 1.2299 \\
G15-023---G18-021 & 1.1826 \\
G18-021---G30-040Self & 1.1675 \\
G15-023---G27-002Self & 1.1120 \\
G27-002Self---G30-040Self & 1.0485 \\
G29-002---G30-040Self & 1.0205 \\
G15-023---G29-002 & 1.0038 \\
G16-039Self---G29-002 & 1.0459 \\
G15-023---G21-014 & 09969 \\
G1-038---G29-002 & 0.9673 \\
\hline b.10 lowest inter genotypic distance. & \\
\hline G6-001---G21-014 & 0.3688 \\
\hline G10-035---G11-033 & 0.3266 \\
G6-001---G25-018 & 0.3142 \\
G6-001---G24-004 & 0.3142 \\
G4-022---G16-039Self & 0.3110 \\
G7-017---G20-010 & 0.2862 \\
G9-032---G10-035 & 0.2679 \\
G4-022---G24-004 & 0.2623 \\
G5-016---G26-015 & 0.2551 \\
G3-019---G5-016 & 0.2055 \\
\hline
\end{tabular}




\section{Clustering}

Table 6 represents the clusters formed by 30 genotypes of onion. It shows that cluster I and IV contained the highest number of genotypes (eight) followed by cluster II (six genotypes), cluster III (five genotypes), and cluster V (three genotypes).

Table 6. Distribution of $\mathbf{3 0}$ genotypes of onion in five clusters.

\begin{tabular}{|c|c|c|}
\hline Cluster & $\begin{array}{c}\text { No. of } \\
\text { genotypes }\end{array}$ & Genotypes and origin \\
\hline $\mathrm{I}$ & 8 & $\begin{array}{l}\text { G1 (India), G2 (Burma), G4 (India) G6 (Pabna), G16 (Burma), } \\
\text { G19 (Burma), G24 (India), G25 (India) }\end{array}$ \\
\hline II & 6 & $\begin{array}{l}\text { G12 (India), G14 (Manikgonj), G22 (Taherpur), G26 (India), } \\
\text { G28 (India), G29 (Pabna) }\end{array}$ \\
\hline III & 5 & $\begin{array}{l}\text { G3 (Burma), G5 (Burma), G13 (India), G15 (India), G30 } \\
\text { (Bangladesh) }\end{array}$ \\
\hline IV & 8 & $\begin{array}{l}\text { G7 (India), G8 (Manikgonj), G9 (Taherpur), G10 (India), G17 } \\
\text { (India), G20 (Burma), G21 (Burma), G23 (Faridpur) }\end{array}$ \\
\hline $\mathrm{V}$ & 3 & G11 (Rajshahi), G18 (Mymensingh), G27 (Pabna) \\
\hline
\end{tabular}

Cluster means for eight characters for 30 genotypes are given in Table 7. Cluster I had the highest mean value for moisture content (87.17). It secured second for number of leaves per plant (10.23) and bulb yield (8.45 t/ha).

Table 7. Cluster mean for eight characters of $\mathbf{3 0}$ genotypes of onion.

\begin{tabular}{l|r|r|r|r|r}
\hline \multirow{2}{*}{\multicolumn{1}{c}{ Components }} & \multicolumn{5}{c}{ Cluster } \\
\cline { 2 - 6 } & \multicolumn{1}{c}{ I } & \multicolumn{1}{c}{ II } & III & IV & V \\
\hline 1 Number of leaves per plant & 10.23 & 10.01 & 11.03 & 10.13 & 9.12 \\
2Leaves length (cm) & 29.54 & 29.86 & 36.04 & 28.01 & 29.11 \\
3 Neck diameter at vegetative stage (mm) & 7.70 & 6.69 & 6.18 & 6.50 & 8.05 \\
4Bulb length (mm) & 40.94 & 37.05 & 45.18 & 38.71 & 36.39 \\
5Moisture content (\%) & 87.17 & 86.10 & 87.10 & 86.45 & 86.62 \\
6Sulfur content (\%) & 0.58 & 0.59 & 0.58 & 0.54 & 0.56 \\
7Plant height (cm) & 55.37 & 54.93 & 61.68 & 53.84 & 48.87 \\
8Bulb yield (t/ha) & 8.45 & 8.31 & 11.32 & 7.63 & 7.10 \\
\hline
\end{tabular}

Cluster II achieved the highest cluster mean values for sulfur content (0.59). However, this stood second in leaf length $(29.86 \mathrm{~cm})$. The highest sulfur containing genotype belongs to cluster II, but the largest bulb producing genotype belongs to cluster III which indicated that the largest bulb always not represent 
higher smell. Smaller bulb producing genotypes belong to cluster $\mathrm{V}$ but this cluster does not contain higher sulfur containing ones which indicated higher sulfur content is not associated with smaller size of bulb. Cluster III contains the highest cluster mean values for most of the characters viz., number of leaves per plant (11.03), leaf length (36.04), bulb length $(45.18 \mathrm{~mm})$, plant height $(61.68$ $\mathrm{cm})$, and bulb yield $(11.32 \mathrm{t} / \mathrm{ha})$. Cluster $\mathrm{V}$ got the highest cluster mean for neck diameter at vegetative stage.

The highest inter-cluster distance was observed (Table 8) between clusters II and I (9.880), followed by II and V (8.715), II and III (7.941), III and V (7.338), and III, and IV (6.830). The intra cluster distance was the highest (0.694) in cluster II followed by that of cluster V (0.469), cluster I (0.463), cluster IV (0.438), and cluster III (0.436). The lowest inter-cluster distances were observed between cluster V (3.302) and I followed by that of cluster II and IV (4.373). Moderate or intermediate distances were found between clusters III and IV (6.830), cluster IV and cluster I (6.271) and V and IIII (7.338). Arunachalam et al. (1984) suggested that the magnitude of heterosis for yield and its components were higher in cross between intermediate divergences than extreme ones. Ramanujam (1974) suggested that there was a fair agreement between the extent of heterosis and the genetic divergence between parents.

Table 8. Average intra and inter cluster distances $\left(D^{2}\right)$ for 30 genotypes of onion.

\begin{tabular}{c|c|c|c|c|c}
\hline Cluster & I & II & III & IV & V \\
\hline I & 0.463 & 9.880 & 5.373 & 6.271 & 3.302 \\
II & & 0.694 & 7.941 & 4.373 & 8.715 \\
III & & & 0.436 & 6.830 & 7.338 \\
IV & & & & 0.438 & 4.411 \\
V & & & & & 0.469 \\
\hline
\end{tabular}

Vector 1 obtained from PCA (Table 9) expressed that neck diameter at vegetative stage $(0.1595)$, plant height $(0.1210)$, and bulb yield $(0.1030)$ were major characters that contribute to the genetic divergence. It was the reflection of first axis of differentiation. In vector 2, sulfur content (2.5490) showed their important role towards genetic divergence. Other characters played minor roles in determining genetic divergence.

Singh et al. (1995) reported individual bulb weight and neck diameter in onion, Mohanty (1999) for number of leaves per plant and Mohanty and Prusti (2001) for weight of bulb and neck thickness in onion contributed predominantly towards total divergence. 
Table 9. Latent vectors for eight principal component characters of $\mathbf{3 0}$ onion genotypes.

\begin{tabular}{lcc}
\hline \multicolumn{1}{c|}{ Characters } & Vector 1 & Vector 2 \\
\hline Number of leaves per plant & 0.3221 & -0.0394 \\
Leaf length (cm) & -0.1823 & -0.2180 \\
Neck diameter at vegetative stage (mm) & 0.1595 & -0.0253 \\
Bulb length (mm) & -0.3033 & -0.0580 \\
Moisture content (\%) & -0.0750 & -.04519 \\
Sulfur content (\%) & -10.6057 & 2.5490 \\
Plant height (cm) & 0.1210 & -0.0222 \\
Bulb yield (t/ha) & 0.1030 & -0.3974 \\
\hline
\end{tabular}

No parallel relationship was found between genetic and geographic divergence, which may be due to continuous exchange of germplasm from one place to another. Differently originated genotypes found in same cluster or genotypes from same origin were dispersed in different clusters. It was observed that group IV and I formed with eight genotypes originated in India, Burma, and Bangladesh. Group V occupied by three genotypes of Bangladesh origin. There are supportive reports made by Mohanty and Prusti (2002), Mohanty (2001) in winter onion, Mohanty (1999) in kharif onion.

Genotypes from India, Burma, and Bangladesh being in different clusters, indicated the broad genetic variability among the genotypes. There was evidence from Shanmugam and Rangasamy (1982) that materials from same origin distributed in different clusters is an indication of broad genetic base of the genotypes belonging to that region.

Considering cluster distance, cluster mean and mean performance of the genotypes for yield, the genotypes G1 and G16 from cluster I, genotypes G12 and G29 from cluster II, genotypes G15 and G30 from cluster III, genotypes G9, G10 and G17 from cluster IV, genotypes G18, G21 and G27 from cluster V may be considered better parents for future hybridization programme.

\section{References}

Arunachalam, V., A. Bandyopadhyay, S.N. Nigam and N.W.Gibbons. 1984. Heterosis in relation to genetic divergence and specific combining ability in ground nut (Arachis hypogaea L.). Euphytica 33:33-39.

Mohanty, B.K. 1999. Analysis of genetic divergence in kharif onion. Indian Journal of Horticulture 58(3): 260-263.

Mohanty, B.K. 2001. Genetic variability, inter-relationship and path analysis in onion. Journal of Tropical Agriculture 39(1): 17-20 
Mohanty, B.K. 2002. Genetic variability, character association and path analysis in bulb onion seed crop. Horticultural Journal 15(2): 61-68

Mohanty, B.K., A.M. Prusti. 2002. Mahalanobis' generalized distance analysis in kharif onion. Orissa Journal of Horticulture. 30(1): 27-29

Ramanujam, S. 1974. Genetic diversity, stability and plant type in pulse crops production. Int. Workshop on grain legumes. ICRISAT, Hyderabad $13^{\text {th }}-16^{\text {th }}$ Jan. pp.167-176

Rao, C.R. 1952. Advanced Statistical Methods in Biometrical Research. John Wiley and Sons, New York. Inc. pp. xvii and 390.

Rao, C, R. 1964. The use and interception of principal component analysis in applied research. Sankhya 22: 317-338.

Shanmugam, A.S and S.R.S. Rangsamy. 1982. Genetic diversity of quantitative characters in green gram (Vigna radiata L Wilczek). Madras. Agric. J. 69 (10): 631636.

Singh, M.C and R.S. Choudhury 1977. Performance Studies of garlic (Allium sativum L.) genotypes. Recent Hort. 1: 74-79.

Sing, D.N., A. Nandi, P. Tripathy, A. Sahu. 1995. Genetic variability and correlation in onion (Allium cepa L.). Indian J. of Agric. Sciences 65(11): 793-796.

Uddin, M.M., A. Samad, M.R. Khan, S. Begum and M.A. Salam. 1985. Correlation and path analysis of yield and yield contributing characters in Brassica species, Bangladesh J. Agric. Res. 10: 71-75. 